\title{
Endodontic management of a mandibular second premolar with three canals using cone beam computed tomography-case report
}

\begin{abstract}
A thorough knowledge of root canal anatomy along with the anatomical variations that may be present is essential for success of endodontic therapy. Unusual presentations in the number of the roots or the canals should be expected in every tooth. Mandibular second premolars are thought of as having a single root and canal. Studies have stated that the prevalence of three canals with three orifices in this tooth is $0.4 \%$ Knowledge of variations in root canal anatomy and accurate diagnosis with novel diagnostic aids like cone beam computed tomography (CBCT) assist in thorough debridement and three dimensional obturation of the root canal system, thus increasing the success rate of nonsurgical endodontic treatment. This article describes the successful management of the right mandibular second premolar with three separate roots diagnosed using CBCT.
\end{abstract}

Keywords: anatomic variations, cone- beam computed tomography, mandibular second premolar, root canal treatment
Volume 2 Issue I - 2018

\author{
Shah Naman \\ Yogita dental college and hospital khed, India
}

Correspondence: Shah Naman, Yogita dental college and hospital khed, India, Tel 9975256357,

Email nhshah2890@gmail.com

Received: September 0I, 2017| Published: February 23, 2018

\section{Introduction}

Every tooth may have variations in relation to the size, number, length, and configuration of the roots and the root canals. The main objective of endodontic therapy is thorough cleaning and shaping of all canal spaces and its complete Obturation with an inert filling material. A wide morphologic divergence of the canal system has been shown to exist. The varying number of canals in different teeth, their anatomy and anastomoses have been reported and studied by various authors over the years. Ingle has reported that the most significant cause of endodontic failures was incomplete canal instrumentation followed by inadequate Obturation ${ }^{1}$ Mandibular premolars may be one of the most difficult teeth in the mouth to treat. ${ }^{2}$ This is primarily due to the variations in internal morphology of the pulp cavity considering the number of root canals, apical deltas, and lateral canals. In addition, the access cavities are relatively small, reducing the visibility. The prevalence of 3 root canals with 3 orifices was reported to be $0.4 \%$ by El Deeb in $1982 .^{3}$ The occurrence of 3 canals in mandibular second premolars has been reported as $0-0.4 \%{ }^{4}$ The occurrence of 3 canals with 3 separate roots with 3 separate foramina (type V, Vertucci) is very rare..$^{5}$ Dentists have been treating the mandibular second premolar under the assumption that they have only one canal and one root. ${ }^{6}$ Hoen and Pink found a $42 \%$ incidence of missed roots/canals in the teeth that needed re treatment. ${ }^{7}$ The use of magnification and use of CBCT offers a tremendous advantage in locating and treating extra canals. ${ }^{8}$

\section{Case Report}

A 35-year-old female patient walked into our clinic with the chief complaint of severe pain in the lower jaw right posterior region since 2 days. Oral examination revealed occlusal caries in the lower right mandibular first premolar and secondary caries in second premolar. The tooth was sensitive to percussion and showed an exaggerated response on cold and electric pulp testing. Radiological findings showed coronal radiolucency involving pulp, widening of periodontal ligament (PDL) space, large pulp chamber without any constriction at cementoenamel junction, the condition was diagnosed as acute irreversible pulpitis with apical periodontitis in both the premolars (Figure 1) Cone-beam computed tomography (CBCT) was carried out for confirming numbers of roots and canals of mandibular right second premolar. The CBCT images were taken out using three-dimensional (3D) Accuitomo scanner (J. Morita, Kyoto, Japan), with Viewer Plus software (J. Morita), which produced a smallest field of view images, to reduce the radiation dosage. A three canals were found, two buccally and one lingually (Figure 2). A non-surgical root canal treatment was planned accordingly. The patient received local anesthesia with $2 \%$ lidocaine and 1:100,000 epinephrine and the rubber dam placement. Following the removal of old filling, careful examination of the pulpal floor revealed three separate mesiobuccal, distobuccal and lingual orifices. The access cavity outline was modified into triangular shape to establish straight-line access for all root canals. The working length was established using Root ZX II (J. Morita, Tokyo, Japan) and confirmed radiographically (Figure 3). Instrumentation is achieved with Hero Shaper (Micro Mega) to size $304 \%$, copious irrigation with $2.5 \% \mathrm{NaOCl}$ and $17 \%$ EDTA was carried out during the instrumentation phase. All canals were dried with sterile paper points and then filling using matching gutta-percha cones and AH-plus sealer (Dentsply Maillefer, Ballaigues, Switzerland) until canal orifices (Figure 4) Postendodontic restoration was done followed by tooth preparation and Zirconia-based full coverage crown cementation. Fifteen months follow-up radiograph revealed satisfactory healing and healthy status of periapical tissues (Figure 5). 


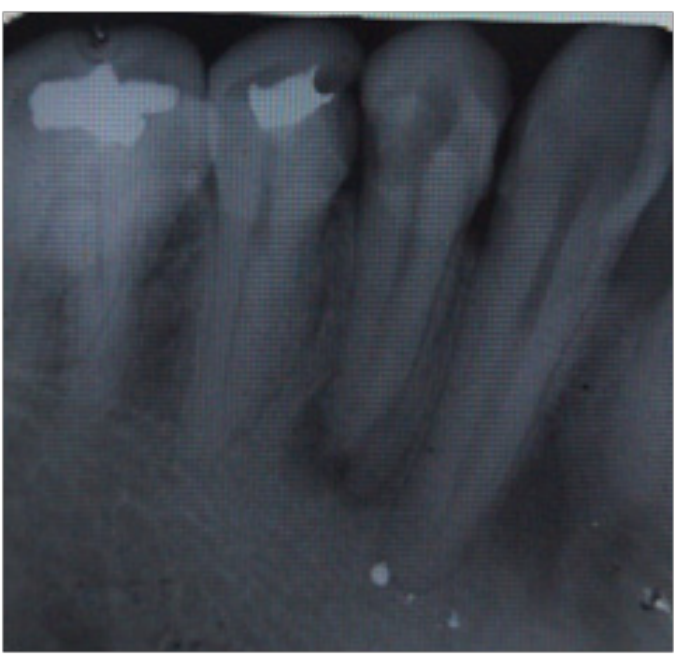

Figure I Pre-operative.
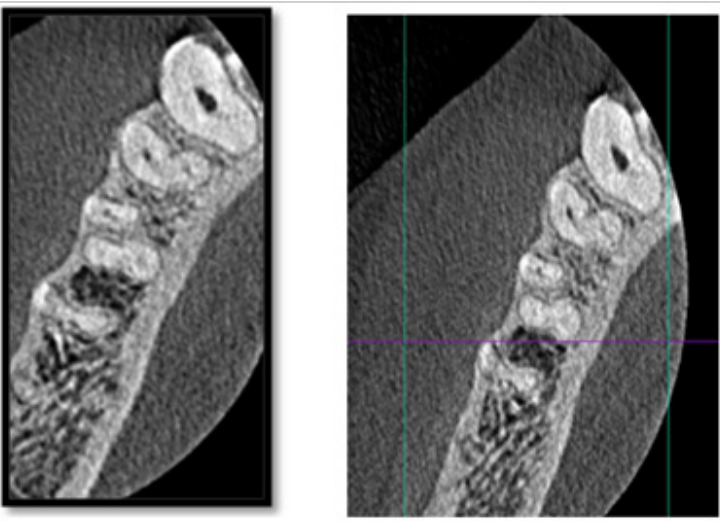

Figure 2 The axial plane of CBCT of \#45 showing three canals. (Apical \& middle Section).

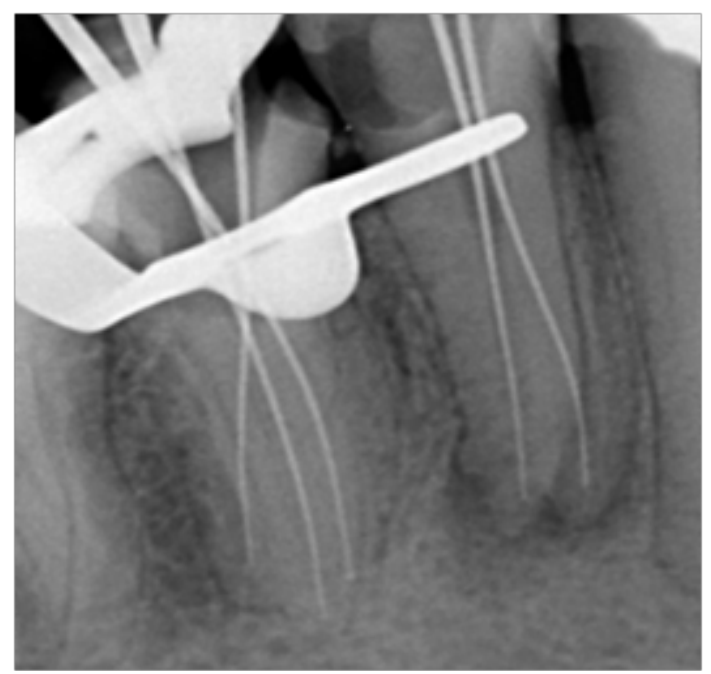

Figure 3 Working length determination.

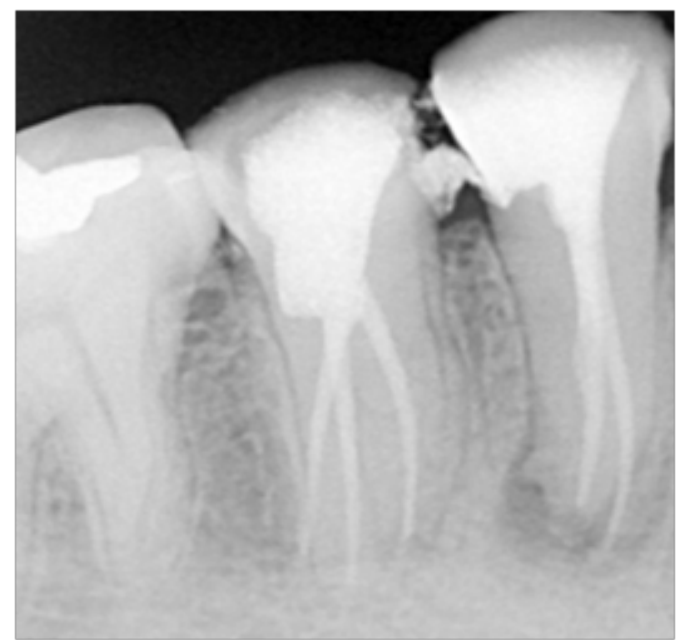

Figure 4 Obturation and final restoration.

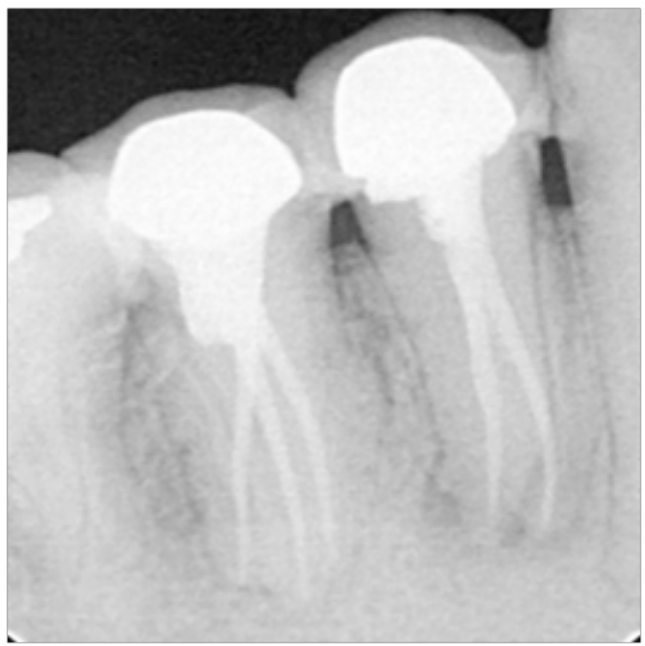

Figure 5 Fifteen month's follow-up radiograph showing Zirconia full coverage Crown and healthy status of eriapical tissues.

\section{Discussion}

The morphology of root canal system of mandibular second premolar is complex. ${ }^{7}$ Ingle stated that canal anatomy accounts for a greater chance of endodontic failures in premolars. ${ }^{8,9}$ Sound knowledge of root canal morphology, vigilant analysis of preoperative radiograph, and careful exploration of pulp chamber floor are essential for the success of root canal treatment. ${ }^{10}$ The advent of three-dimensional imaging techniques such as CBCT, dental operating microscope/ loupes, fiber optic transillumination as well as recent developments in root canal instrumentation, and Obturation techniques made this challenging task quite simple. ${ }^{11}$ The introduction of CBCT resulted in a paradigm shift in the field of endodontics. CBCT provides a small field of view images at low-radiation dose with good spatial resolution. ${ }^{12} \mathrm{An}$ additional canal should be suspected whenever there is a sudden narrowing of root canal system or if the ${ }^{13}$ working length file appears off center in the radiograph. ${ }^{14}$ Good preoperative radiographs 
taken in two or three angulations, and careful interpretation of root outline and PDL space helps in identifying extra roots. ${ }^{15}$ Analysis of dentinal map and color change on the floor of pulp chamber also help in the detection of extra canals. ${ }^{7}$ Orifice enlargement and preflaring reduces curvature and produces a straight line access to curved apical portion. ${ }^{16,17}$ The more apically a root canal divides, more difficult it is to access and obturate; therefore, care should be taken to maintain patency during obturation. ${ }^{18}$ Careful interpretation of diagnostic periapical radiographs taken at more than one angle is important to detect teeth morphological variations. ${ }^{19,20}$ Furthermore, use of magnification with the help of a loupe or a microscope and visual enhancement with the use of fiber optics, sodium hypochlorite bubble technique and staining with $1 \%$ methylene blue dye might help to locate additional root canals. ${ }^{21-23}$

\section{Conclusion}

The success of endodontic therapy relies on accurate diagnosis, thorough chemomechanical debridement, and proper obturation of root canal system. Mandibular premolars have high-failure rate due to their extreme variations in root canal anatomy. Novel imaging modalities such as CBCT, magnification, modified obturation, and postendodontic restorative techniques aids in the successful management of these rare cases.

\section{Acknowledgement}

None.

\section{Conflict of interest}

The author declare that they have no conflict of interest.

\section{References}

1. Vertucci FJ. Root canal morphology and its relationship to endodontic procedures. Endod Topics. 2005;10(1):30-29.

2. Cantatore G, Berutti E, Castellucci A. Missed anatomy: Frequency and clinical impact. Endod Topics. 2006;15(1):30-31.

3. Friedman S. Prognosis of initial endodontic therapy. Endod Topics. 2002;2:59-88

4. Slowey RR. Root canal anatomy. Road map to successful endodontics. Dent Clin North Am. 1979;23(4):555-573.

5. Cleghorn BM, Christie WH, Dong CC. The root and root canal morphology of the human mandibular second premolar: A literature review. J Endod. 2007;33(9):1031-1037.

6. Serman NJ, Hasselgren G. The radiographic incidence of multiple roots and canals in human mandibular premolars. Int Endod J. 1992;25(5):234 237.
7. Zaatar EI, Alkandari AM, Alhmaidah S, et al. Frequency of endodontic treatment in Kuwait: Radiographic evaluation of 846 endodontically treated teeth. J Endod. 1997;23(7):453-456.

8. Sert S, Bayirli GS. Evaluation of the root canal configurations of the mandibular and maxillary permanent teeth by gender in the Turkish population. J Endod. 2004;30(6):391-398.

9. Caliskan MK, Pehlivan Y, Sepetcioglu F, et al. Root canal morphology of human permanent teeth in a Turkish population. $J$ Endod. 1995;21(4):200-204.

10. Shapira Y, Delivanis P. Multiple-routed mandibular second premolars. $J$ Endod. 1982;8:231-232.

11. Fischer GM, Evans CE. A three-routed mandibular second premolar. Gen Dent. 1991;40:139-140.

12. Rödig T, Hülsmann M. Diagnosis and root canal treatment of a mandibular second premolar with three root canals. Int Endod J. 2003;36(12):912-919.

13. Mukhaimer R. Bilateral mandibular second premolars with three separate roots. Saudi Endod J. 2012;2(3):156-160.

14. Gandhi B, Patil AC. Root canal treatment of a mandibular second premolar with three roots and canals-An anatomic variation. J Dent (Tehran). 2013;10(6):569-574.

15. Fathi Z, Rahimi S, Tavakoli R, et al. A three-rooted mandibular second premolar: A case report. J Dent Res Dent Clin Dent Prospects. 2014;8(3):184-186.

16. Hariharavel V, Kumar AA, Ganesh C, et al. Root canal treatment of mandibular second premolar with three separate roots and canals using spiral computed tomographic. Case Rep Dent. 2014;2014:816576.

17. Paul B, Dube K. Endodontic treatment of a mandibular second premolar with three roots and three canals. Case Rep Dent. 2014;2014:973410.

18. Saberi EA, Rasooli H, Movassagh Z. Retreatment of a mandibular second premolar with three roots: A case report. Iran Endod J. 2014;9(2):158160.

19. Slowey RR. Radiographic aids in the detection of extra root canals. Oral Surg Oral Med Oral Pathol. 1974;37(5):762-772.

20. Fava LR, Dummer PM. Periapical radiographic techniques during endodontic diagnosis and treatment. Int Endod J. 1997;30(4):250-261.

21. Patel S. New dimensions in endodontic imaging: Part 2. Cone beam computed tomography. Int Endod J. 2009;42(6):463-475.

22. Durack C, Patel S. Cone beam computed tomography in endodontics Braz Dent J. 2012;23(3):179-191.

23. Carr GB. Microscopes in endodontics. $J$ Calif Dent Assoc. 1992;20(11):55-61. 